\title{
Implementation of a National Semen Testing and Counseling Program for Male Ebola Survivors — Liberia, 2015-2016
}

\begin{abstract}
Lawrence J. Purpura, MD ${ }^{1,2}$; Moses Soka, MD³; April Baller, $\mathrm{MBBCh}^{4}$; Stephen White, MSc ${ }^{5}$; Emerson Rogers ${ }^{3}$; Mary J. Choi, MD ${ }^{1}$; Nuha Mahmoud, MD ${ }^{4}$; Christine Wasunna, $\mathrm{PhD}^{5}$; Moses Massaquoi, MD 3 ; Kristin Vanderende, PhD ${ }^{2,6}$; Jomah Kollie, MPH-HSMP4; Straker Dweh5; Philip Bemah, MD³; Athalia Christie, MIA ${ }^{7}$; Victor Ladele, MBBS ${ }^{4}$; Onyekachi Subah'; Satish Pillai, MD ${ }^{8}$; Margaret Mugisha, MPH ${ }^{4}$; Jonathan Kpaka ${ }^{5}$; Stuart Nichol, $\mathrm{PhD}^{1}$; Ute Ströher, $\mathrm{PhD}^{1}$; Neetu Abad, PhD ${ }^{9}$; Shauna Mettee-Zarecki, MSN, MPH ${ }^{10}$; Jeff A. Bailey, MD, PhD ${ }^{5}$; Pierre Rollin, MD ${ }^{1}$; Barbara Marston, MD ${ }^{11}$; Tolbert Nyenswah, $\mathrm{MPH}^{3}$; Alex Gasasira, MBChB ${ }^{4}$; Barbara Knust, DVM ${ }^{1}$; Desmond Williams, MD, PhD ${ }^{11}$
\end{abstract}

According to World Health Organization (WHO) data, the Ebola virus disease (Ebola) outbreak that began in West Africa in 2014 has resulted in 28,603 cases and 11,301 deaths (1). In March 2015, epidemiologic investigation and genetic sequencing in Liberia implicated sexual transmission from a male Ebola survivor, with Ebola virus detected by reverse transcription-polymerase chain reaction (RT-PCR) 199 days after symptom onset $(2,3)$, far exceeding the 101 days reported from an earlier Ebola outbreak (4). In response, WHO released interim guidelines recommending that all male survivors, in addition to receiving condoms and sexual risk reduction counseling at discharge from an Ebola treatment unit (ETU), be offered semen testing for Ebola virus RNA by RT-PCR 3 months after disease onset, and every month thereafter until two consecutive semen specimens collected at least 1 week apart test negative for Ebola virus RNA (5). Male Ebola survivors should also receive counseling to promote safe sexual practices until their semen twice tests negative. When these recommendations were released, testing of semen was not widely available in Liberia. Challenges in establishing and operating the first nationwide semen testing and counseling program for male Ebola survivors included securing sufficient resources for the program, managing a public health semen testing program in the context of ongoing research studies that were also collecting and screening semen, identification of adequate numbers of trained counselors and appropriate health communication messages for the program, overcoming Ebola survivor-associated stigma, identification and recruitment of male Ebola survivors, and operation of mobile teams.

In July 2015, the Men's Health Screening Program (MHSP) was launched in Liberia ( 6 . MHSP is a public health program that provides 1) semen testing for Ebola virus RNA using realtime RT-PCR (rRT-PCR) to male Ebola survivors; 2) counseling on safe sexual practices; 3) condoms and instructions on condom use; and 4) referrals for health care services. The program is a collaboration between the Liberian Ministry of Health (MOH), CDC, WHO, and the Academic Consortium to Combat Ebola in Liberia and operates at Redemption Hospital in Montserrado County, Phebe Hospital in Bong County, and Tellewoyan Hospital in Lofa County. All male
Ebola survivors aged $\geq 15$ years with proof of survivorship (e.g., a discharge certificate from an ETU) are eligible to enroll. In accordance with WHO guidelines (5), participants graduate from the program after receiving two consecutive negative Ebola virus RNA rRT-PCR results on semen specimens collected at least 1 week apart. The primary location for service delivery is the program clinic; however, Ebola survivors who are unable to travel to the clinic are offered services at a location of their choosing by a mobile team that includes a counselor and a semen technician. Participants receiving services from the mobile team are also offered the opportunity to include their sexual partners in their counseling sessions.

At the program's inception, little was known about the duration of Ebola virus persistence in semen, and several research institutions recruited Ebola survivors into studies designed to evaluate this. These studies often operate at the same time and in the same counties as MHSP. Because these research studies and MHSP use different RT-PCR platforms to test semen, and the potential for differing interpretations of test results exists, it was necessary to inform MHSP participants before graduation that they might receive different results if they chose to enroll in another semen testing service. To minimize differences in test results, MHSP collaborated with the research institutions providing semen testing to harmonize test interpretation and counseling messages.

As of May 2015, the longest reported time after the onset of an Ebola survivor's symptoms to collection of a semen specimen that tested positive for Ebola virus RNA was 6 months (2). The peak of the Ebola outbreak in Liberia occurred approximately 9 months before the program began; thus, the initial expectation was that the program would need to operate for 6 months, and budgets were prepared accordingly. However, as program operations approached the 6-month mark, 24 (11\%) of the 228 enrolled participants had produced at least one semen sample that tested positive for Ebola virus RNA; among these, only four had two consecutive negative specimens. In response, $\mathrm{MOH}$ extended program operations; however, the inability to accurately approximate the end of program operations posed program planning and budgeting challenges. Currently, the program is funded through December 2016. 
Because no validated risk reduction counseling protocols or scripts had been developed especially for Ebola survivors in Liberia, risk reduction materials for MHSP were adapted from the Sierra Leone study of persistence of Ebola virus RNA in semen ( 7 ). To ensure that messages were culturally appropriate, feedback on all program materials was solicited from a survivor advisory board of eight male and two female Ebola survivors from several highly affected counties in Liberia. Identification of counselors was hindered by the limited availability of trained mental health counselors in Liberia; in addition, the need to rapidly implement program services precluded training new mental health counselors. MHSP trained two of Redemption Hospital's mental health counselors to provide behavioral counseling to MHSP participants, which increased Liberia's current capacity to deliver specialized behavioral counseling and helped to ensure its availability should another outbreak occur.

In the aftermath of the Ebola outbreak, many Ebola survivors faced stigma and were shunned by their families and ostracized by their communities; the biologic possibility of sexual transmission of Ebola virus further exacerbated the fear and mistrust of Ebola survivors (8). In an effort to minimize stigma among program participants, the program name (Men's Health Screening Program) intentionally avoided using the terms "Ebola" and "survivor." At the recommendation of the advisory board, the program is not advertised through the radio. Instead, information about the program is disseminated by word-of-mouth through Ebola survivors or by directly contacting survivors listed in the national Ebola survivor registry.* Initial efforts to recruit Ebola survivors were limited to telephoning men listed in the survivor registry, which includes contact information for 527 laboratory-confirmed male Ebola survivors in Liberia. To be included in the registry, a survivor must have been admitted to an ETU, tested positive for Ebola virus infection, later discharged from an ETU, and then added to the registry. By the time the MHSP began operations in July 2015, much of the contact information in the registry, which was collected at the time of ETU admission, was no longer valid. In addition, it is certain that the registry underestimated the actual number of Ebola survivors in Liberia, because not all survivors necessarily met the registry requirements; in fact, only half of MHSP participants who produced an Ebola virus RNA rRT-PCR-positive semen specimen were listed in the registry.

\footnotetext{
${ }^{*}$ The Ebola survivor registry was only used to identify and contact potential participants, and not as MHSP enrollment criteria. ETU discharge certificates were used as enrollment criteria; not all survivors with ETU certificates were in the survivor registry.
}

\section{Summary}

What is already known about this topic?

Persistence of Ebola virus in semen of survivors of Ebola virus disease (Ebola) was documented before the 2014 outbreak in West Africa; however, the duration of viral persistence continues to exceed previous estimates. To prevent sexual transmission of Ebola, semen testing services have been established in Liberia, Sierra Leone, and Guinea.

What is added by this report?

In 2015, the first nationwide semen testing and counseling program for male Ebola survivors, the Men's Health Screening Program, was established in Liberia. Challenges in establishing and operating the program included securing sufficient resources for the program, managing a public health semen testing program in the context of ongoing research studies (including collecting and screening semen), identifying adequate numbers of trained counselors and appropriate health communication messages for the program, overcoming Ebola survivorassociated stigma, identifying and recruiting male Ebola survivors, and operating mobile teams. Approximately $80 \%$ of enrollees have graduated from the program.

What are the implications for public health practice?

Engagement with the survivor community, communication, and flexibility were important to the success of the program. Lessons learned during the establishment of the MHSP in Liberia might inform the planning and implementation of future semen testing programs for other sexually transmissible diseases.

As a result of the limited recruitment strategy, enrollment began to decline at the Redemption Hospital Montserrado County site in November, 2015 (Figure). To address this issue, a focus group discussion with members of the survivor advisory board identified the need for closer engagement with other Ebola survivor associations to increase awareness about the program. Since that time, MHSP has been meeting regularly with representatives of the survivor associations, and representatives from these associations have been hired to facilitate identification and recruitment of male survivors into the program.

Overall, 20\% of MHSP participants chose to receive services via mobile teams. Reported benefits of this service included convenience, privacy, and reduced waiting times; the mobile teams also provided a means for clinic-based clients who had challenges related to transportation to remain in the program. Five participants who received services at home chose to invite their sexual partners to participate in the behavioral counseling sessions. Joint counseling was reported to facilitate the participant's adherence to safe sex practices, and as a result, MHSP now offers joint counseling to clinic-based participants as well. 
FIGURE. Number of male Ebola virus disease survivors enrolled at the Men's Health Screening Program Redemption Hospital site, by month - Montserrado County, Liberia, July 2015-June 2016

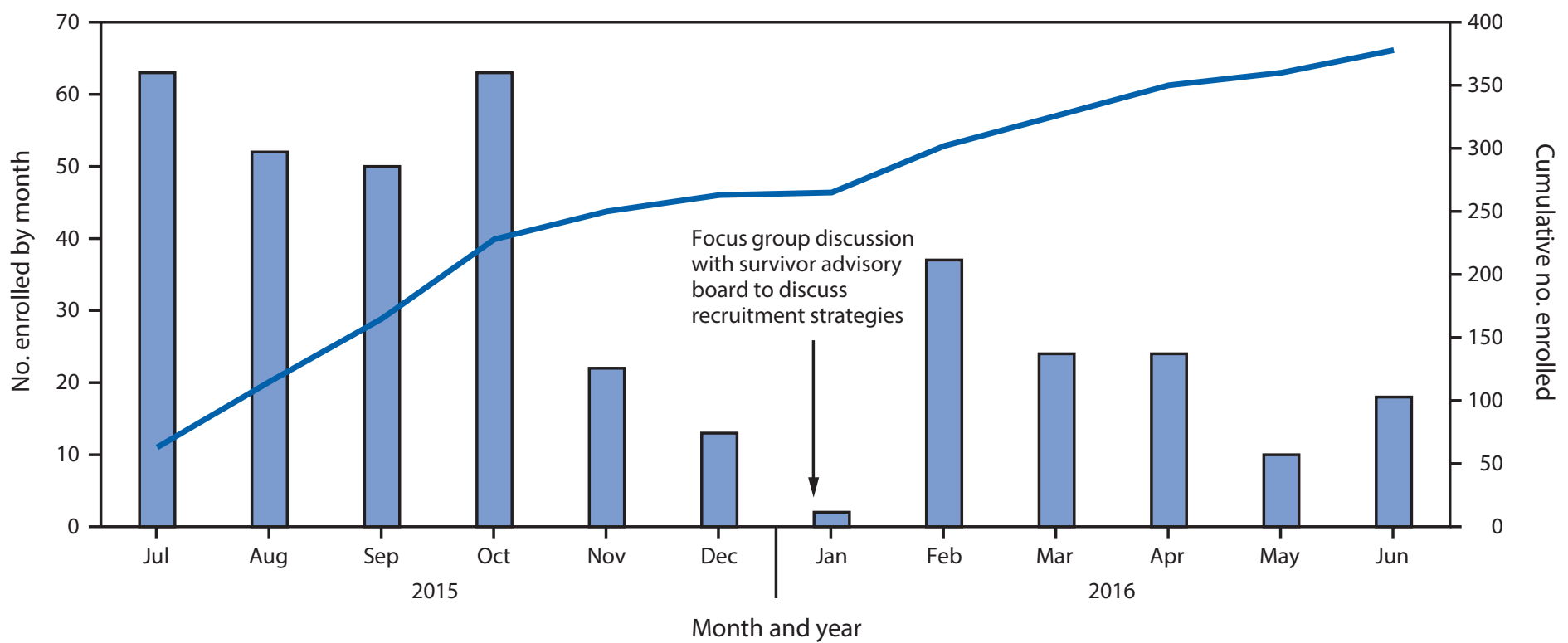

Despite these benefits, mobile service visits have not been as efficient as clinic visits. For example, on a typical day, the clinic is able to provide services to 15 participants; whereas, the mobile team is only able to provide services to four. In addition, in many cases, the participant is not present when the mobile team arrives, and the presence of friends and family members in the home at the time of the mobile team visit can compromise participant privacy. To improve efficiency, the mobile team attempts to schedule visits based on the geographic location of participants' homes to reduce travel time, and telephones participants the day before the scheduled visit to remind them of the appointment. Counselors remind participants of the importance of identifying a time and place to meet where they can talk privately.

\section{Discussion}

Since the launch of MHSP in July 2015, approximately 500 male Ebola survivors have been enrolled in the program at the Montserrado, Bong, and Lofa County sites, and approximately $80 \%$ have graduated from the program; more than $95 \%$ of graduates reported that they would refer a friend or family member to MHSP. Soliciting input from members of the survivor community regarding program planning, counseling messages, and avoidance of stigma was critical to gaining acceptance of the program and enhancing participant recruitment.
Hiring and training local staff members can enhance local capacity, creating a pool of trained personnel who can respond in the aftermath of another public health crisis. The use of a mobile team and joint counseling sessions with partners were effective in providing privacy and facilitating counseling. Lessons learned during the establishment of MHSP in Liberia might inform the planning and implementation of future semen testing programs for other sexually transmissible diseases.

\footnotetext{
${ }^{1}$ Division of High Consequence Pathogens and Pathology, National Center for Emerging and Zoonotic Infectious Diseases, CDC; ${ }^{2}$ Epidemic Intelligence Service, CDC; ${ }^{3}$ Liberian Ministry of Health; ${ }^{4}$ World Health Organization; ${ }^{5}$ Academic Consortium Combating Ebola in Liberia; ${ }^{6}$ Division of Violence Prevention, National Center for Injury Prevention and Control, CDC; ${ }^{7}$ Office of the Director, Center for Global Health, CDC; ${ }^{8}$ Division of Preparedness and Emerging Infections, National Center for Emerging and Zoonotic Infectious Diseases, CDC; ${ }^{9}$ Division of Sexually Transmitted Disease Prevention, National Center for HIV/AIDS, Viral Hepatitis, STD, and TB Prevention, CDC; ${ }^{10}$ Division of Emergency Operations; ${ }^{11}$ Division of Global Health Protection and Security, Center for Global Health, CDC.

Corresponding author: Lawrence Purpura, yxp0@cdc.gov, 404-639-8280.

\section{References}

1. World Health Organization. Ebola situation report. Geneva, Switzerland: World Health Organization; 2016. http://apps.who.int/ebola/currentsituation/ebola-situation-report-2-march-2016

2. Christie A, Davies-Wayne GJ, Cordier-Lassalle T, et al. Possible sexual transmission of Ebola virus_Liberia, 2015. MMWR Morb Mortal Wkly Rep 2015;64:479-81.
} 
3. Mate SE, Kugelman JR, Nyenswah TG, et al. Molecular evidence of sexual transmission of Ebola virus. N Engl J Med 2015;373:2448-54. http:// dx.doi.org/10.1056/NEJMoa1509773

4. Rodriguez LL, De Roo A, Guimard Y, et al. Persistence and genetic stability of Ebola virus during the outbreak in Kikwit, Democratic Republic of the Congo, 1995. J Infect Dis 1999;179(Suppl 1):S170-6. http://dx.doi. org/10.1086/514291

5. World Health Organization. Interim advice on the sexual transmission of the Ebola virus disease. Geneva, Switzerland: World Health Organization; 2016. http://www.who.int/reproductivehealth/topics/rtis/ ebola-virus-semen/en/
6. Soka MJ, Choi MJ, Baller A, et al. Prevention of sexual transmission of Ebola in Liberia through a national semen testing and counselling programme for survivors: an analysis of Ebola virus RNA results and behavioural data. Lancet Glob Health 2016;4:e736-43. http://dx.doi. org/10.1016/S2214-109X(16)30175-9

7. Deen GF, Knust B, Broutet N, et al. Ebola RNA persistence in semen of Ebola virus disease survivors-preliminary report. N Engl J Med 2015. Epub October 14, 2015. http://dx.doi.org/10.1056/NEJMoa1511410

8. Sprecher A. Handle survivors with care. N Engl J Med 2015. Epub October 14, 2015. http://dx.doi.org/10.1056/NEJMe1512928 